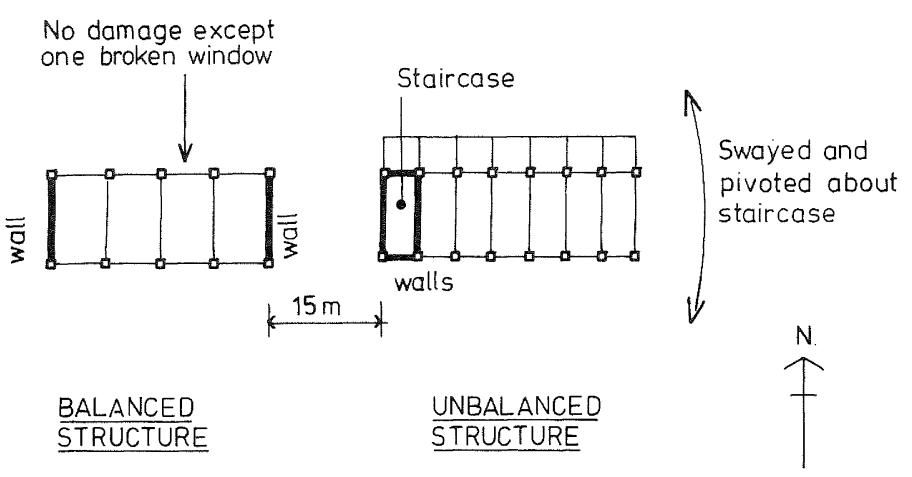

PLAN OF TWO BUILDINGS SHOWN IN PHOTOGRAPH BELOW

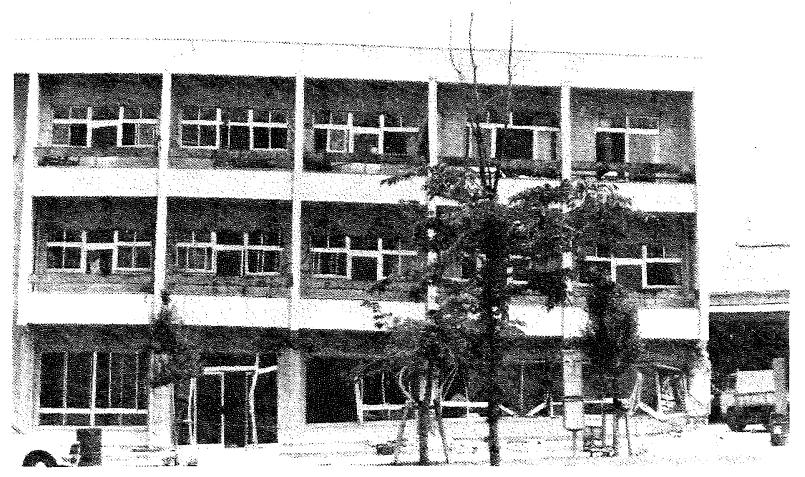

VIEẂ OF SOUTH WALL

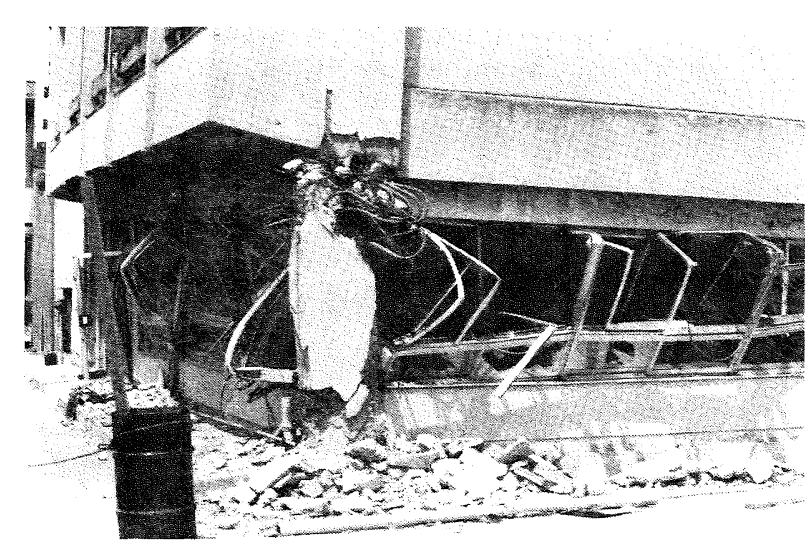

DAMAGE TO CORNER COLUMN
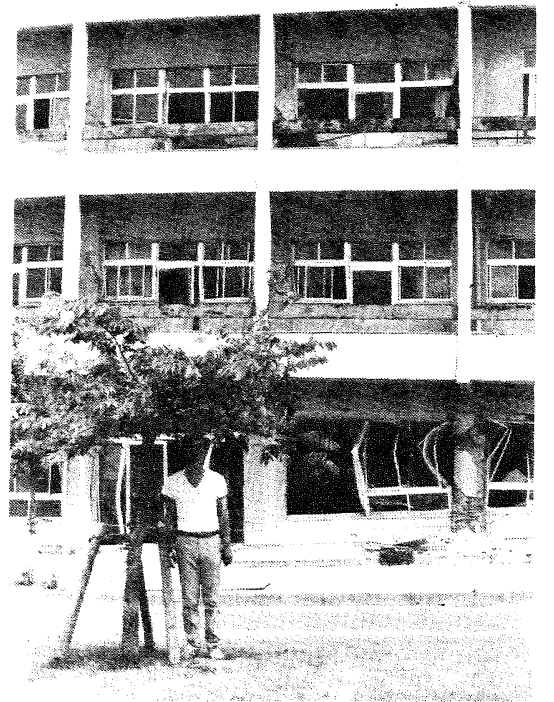

PHOTOGRAPHER IN FRONT OF SOUTH WALL

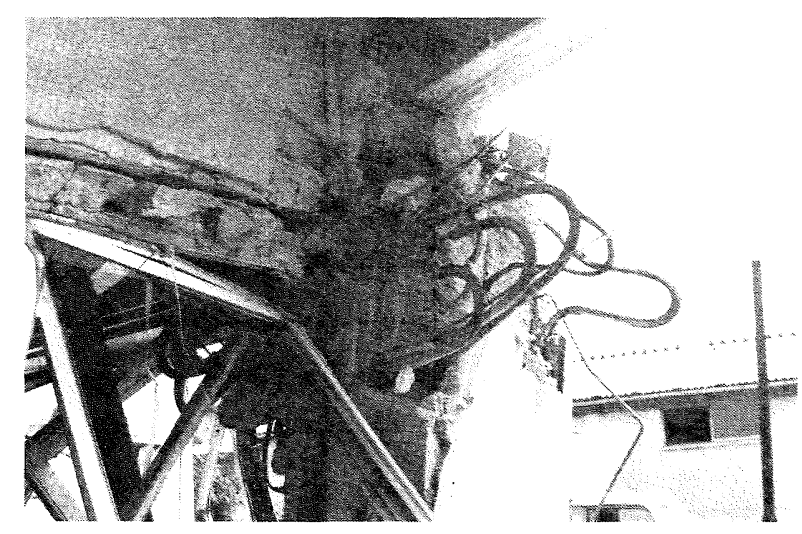

DETAIL OF CORNER COLUMN

\title{
EARTHQUAKE DAMAGE AT SENDAI JUNE 1978
}

On 12 June, 1978 an earthquake of magnitude 7.5 occurred about $100 \mathrm{~km}$ off the east coast of Honshu, the main island of Japan. The earthquake caused widespread damage in Sendai, a city of some 600,000 inhabitants, which is located about $350 \mathrm{~km}$ north of Tokyo and $250 \mathrm{~km}$ south of Hachinohe (where extensive damage occurred in the 1968 Tokachi-oki earthquake. According to press reports, only 20 people lost their lives in Sendai. These photographs and sketches of building damage in sendai are by Doukou Hayashi of Yokoyama Consulting Engineers, Tokyo, and are reproduced here courtesy of Mr. W. P. Edwards of Wellington. 


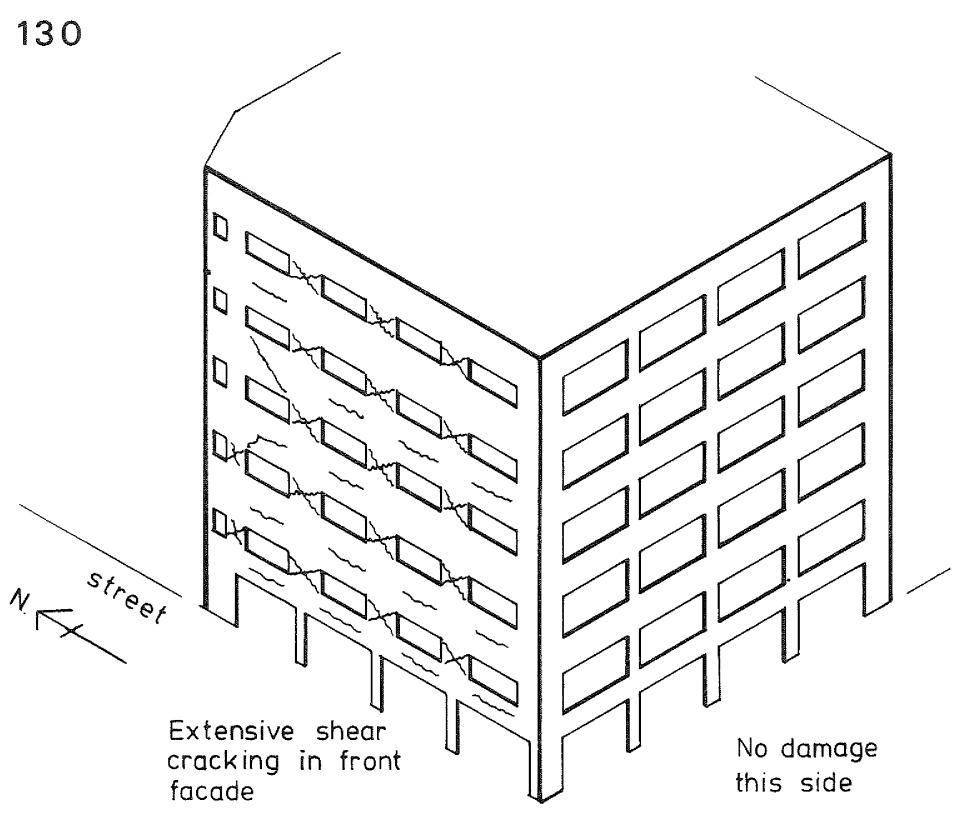

SKETCH OF BUILDING SHOWING LOCATION OF DAMAGE

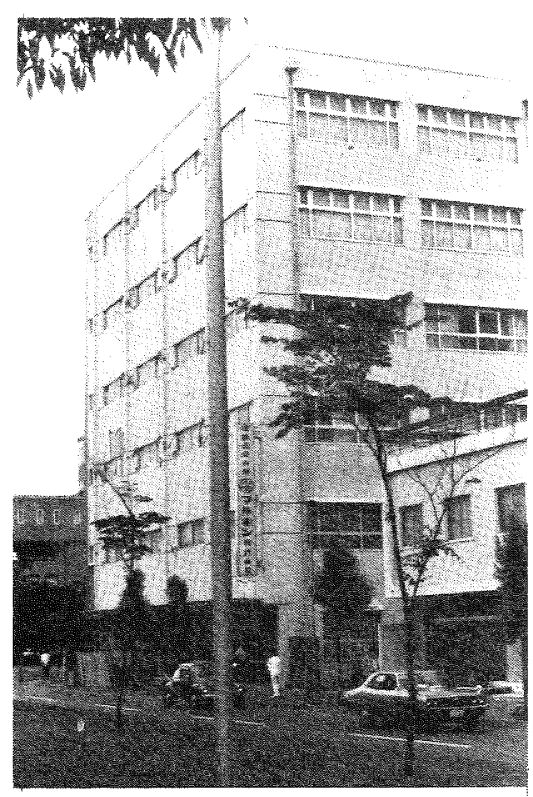

FRONT AND SOUTH SIDE

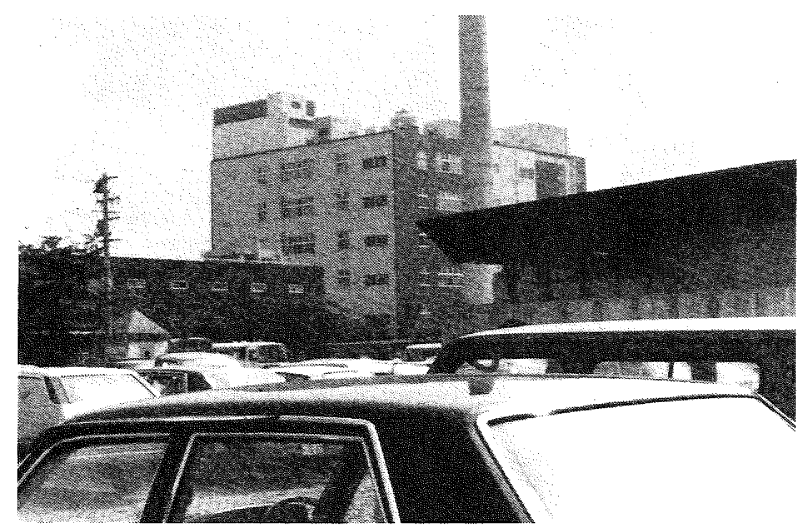

BACK (EAST) SIDE

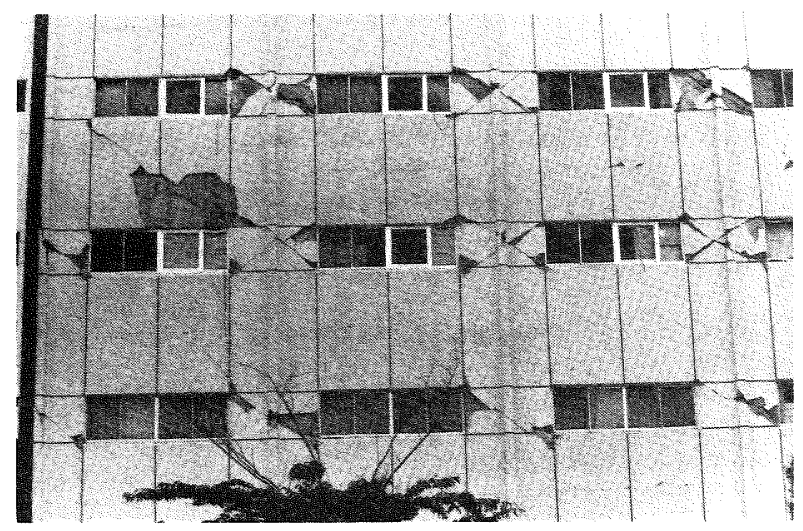

SHEAR CRACKING FRONT WALL

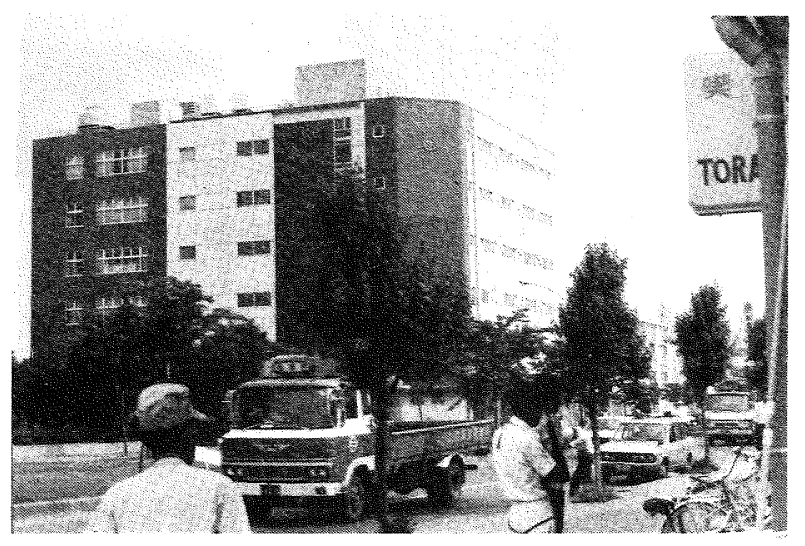

NORTH SIDE

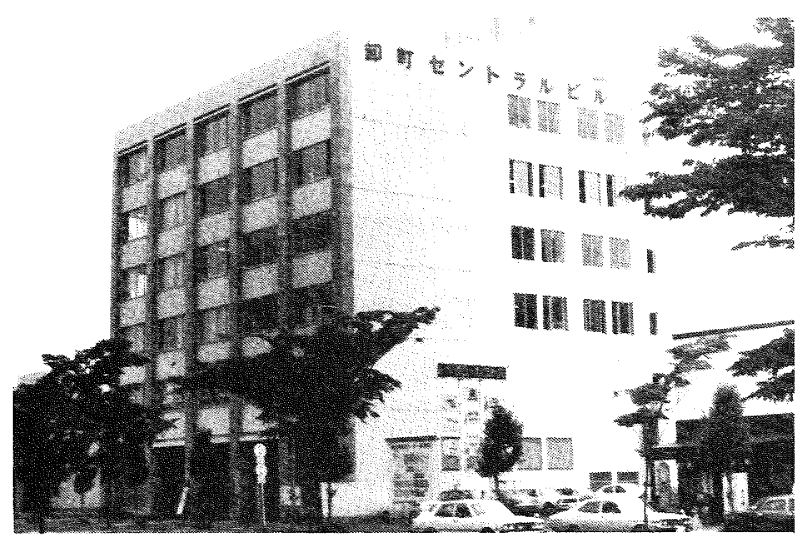

NO DAMAGE TO BUILDING OPPOSITE 